\title{
RISKMETRICSTM METHODOLOGY IN ASSESSMENT \\ OF INVESTMENT RISK ON CAPITAL MARKETS
}

\author{
Grzegorz Mentel, Ph.D. \\ Department of Quantitative Methods \\ Faculty of Management \\ Rzeszow University of Technology \\ Powstańców Warszawy 8, 35-959 Rzeszów \\ e-mail: gmentel@prz.edu.pl
}

Received 25 October 2010, Accepted 20 Apri1 2011

\begin{abstract}
In the article the author has presented the methodology of assessment of market risk connected with investing in all sorts of financial instruments such as: shares, bonds and other derivatives, e.g. RiskGrade (RG). The measure has been introduced by RiskMetrics. The article presents the application of RiskGrades methodology while choosing the optimum investment portfolio for a Polish investor who invests in shares in the Warsaw Stock Exchange. Moreover, some other risk measures have been discussed which describe the efficiency of the optimum financial portfolio.
\end{abstract}

Keywords: risk, capital market.

JEL classification: C01, C51, C53. 


\section{RiskGrades definition}

RiskGrade $(R G)$ is a comparative measure of investment risk in all types of financial instruments. It is a risk measure based upon the volatility formulated by standard deviation determined for the logarithmic (annual) returns of the researched financial instruments. The bigger volatility, the higher values of RiskGrade, and also the higher risk of monetary investment in a given instrument for the potential investor. It is a good measure as it is dynamic, which enables the investor to control the risk of a given investment. It also gives an opportunity to compare the risk of investment within the given group of financial instruments (e.g. shares) as it is a comparative measure. RiskGrade is defined by the following formula ${ }^{1}$ :

$$
R G_{t}^{(i)}=\frac{\sigma_{t, 252}^{(i)}}{\sigma_{\text {base }}} \cdot 100
$$

where:

$$
\begin{aligned}
& \sigma_{t, 252}^{(i)}-\text { standard deviation of the annual (252-day) logarithmic returns: } r_{t, 252}^{(i)}=\ln \left(\frac{C_{t+252}^{(i)}}{C_{t}^{(i)}}\right) \\
& \text { for prices of the instrument researched, } \\
& \sigma_{\text {base }}-\text { benchmark volatility accepted as a benchmark. }
\end{aligned}
$$

Estimates for $\sigma_{t, 252}^{(i)}$ in (1) are determined from the following formula:

$$
\begin{gathered}
\sigma_{t, 252}^{(i)}=\sqrt{252} \cdot \sigma_{t, 1}^{(i)}, \\
\sigma_{t, 1}^{(i)}=\sqrt{\frac{1-\lambda}{1-\lambda^{n}} \sum_{j=0}^{n} \lambda^{j} \cdot r_{t-j, 1}^{2}}
\end{gathered}
$$

In the formula (2) the constant of "smoothing" $\lambda=0,97$ has been adopted as the estimator of standard deviation for daily logarithmic returns of the researched financial instrument and $n=151$ of the last historical observations has been taken into account (it is determined by RiskMetrics as a sufficient number of historical observations) (Figure 1).

This estimator was derived assuming that the logarithms for the daily price changes of the researched financial instrument are modeled by Random Walk, and also that the expected daily returns of this instrument equal zero $\left(E\left[r_{t, 1}^{(i)}\right]=0\right)$.

Benchmark volatility in relation to which the volatility of the researched financial instrument is compared while calculating $R G$ was determined in the following way. The group of 21 international indices for the financial markets with the highest capitalization were taken into account (the data was obtained from the statistics of the London Stock Exchange). For each index the $\bar{\sigma}_{t, 252}^{(j)}$ was determined, which is the average standard deviation for its annual 


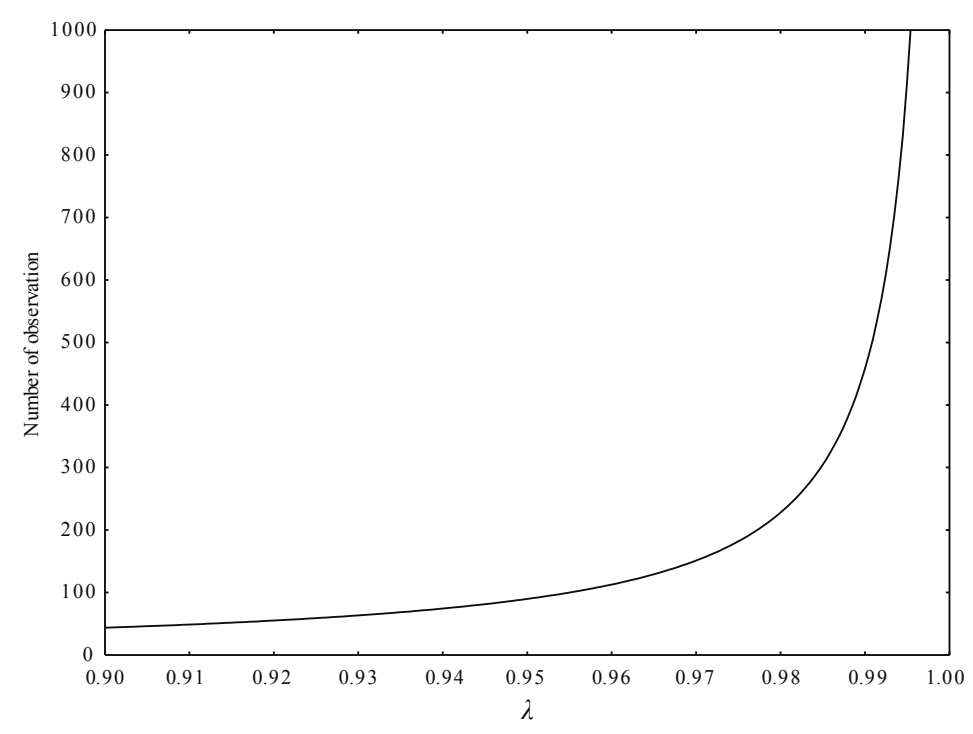

Fig. 1. Number of historical observations as a function of a smoothing constant $\lambda$

Source: own research on the basis of RiskGrades ${ }^{\mathrm{TM}}$ Technical Document, Second edition, February 2001.

logarithmic returns (calculated by means of (2)) in the period of 5 years, that is from January 1995 to December 1991. As a benchmark volatility weighted average (with the weights resulted from the market capitalization) calculated from the annual volatility of the researched group of indices in a given period of time was adopted:

$$
\sigma_{\text {base }}=\sum_{j=1}^{21} \omega_{j} \cdot \bar{\sigma}_{t, 252}^{(j)}
$$

In the considered 5-year-period, the weighted average annual volatility of the group of the researched indices was about $20[0 \%]^{2}$. Therefore, the basic average in the formula (1) is $\sigma_{\text {benchmark }}$ $=0.2$, that is, $R G$ is finally determined from the following formula:

$$
R G_{t}^{(i)}=\frac{\sqrt{252} \cdot \sigma_{t, 1}^{(i)}}{0.2} \cdot 100
$$

Table 1 shows the composition of the group of international indices with already determined average annual volatility for each index in the period from 1995 to 1999 and weighted average benchmark volatility. 


\section{Assessment of investment risk in shares exemplified by partnerships of the WIG20 index}

RiskGrade methodology was applied to assess the risk of investing in shares for the Polish investor who invests in the Warsaw Stock Exchange in the shares of partnerships with the highest capitalization (those which have created WIG20 index). In the analyses the historical records of stock exchange quotations of these partnerships from January 2000 to April 2003 were taken into account. While doing the initial risk assessment on the basis of RiskGrade it is worth looking closer at the values of the basic descriptive statistics determined on the basis of $R G$ values from June 2000 to April 2003.

Table 1. The composition of the group of international indices calculated on their basic value of the benchmark volatility

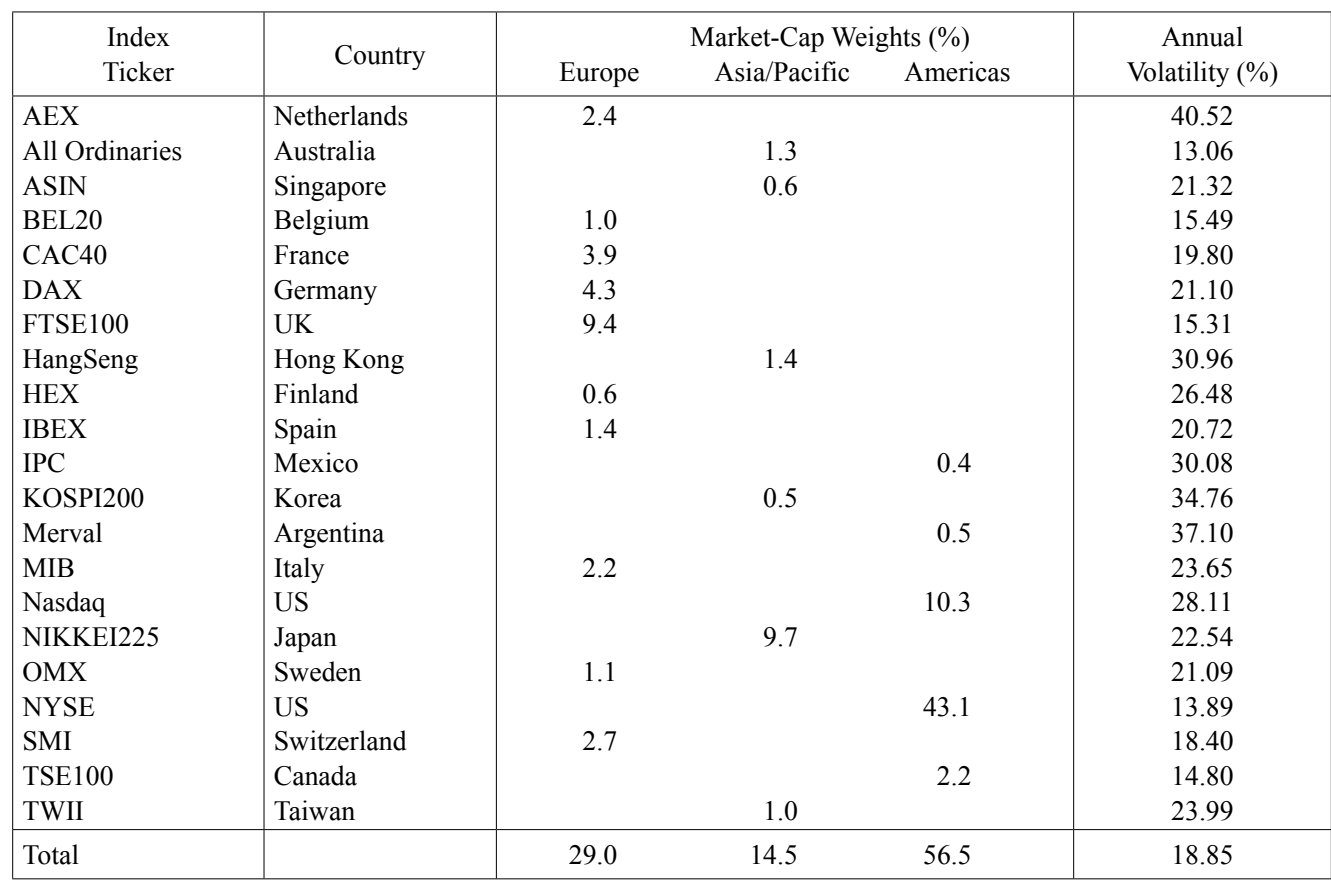

Source: RiskGrades Technical Document, RiskMetrics 2000, (www.riskmetrics.com).

On the basis of the results obtained (in Table 2) we can divide the partnerships of WIG 20 index into three main groups: those with minimum, average and maximum risk. The division has been done as the result of analyses of average $R G$ for the above mentioned time horizon. 
Table 2. Minimum, maximum and average $(R G)$ for partnerships of WIG20 index

\begin{tabular}{|l|c|c|c|c|}
\cline { 2 - 5 } \multicolumn{1}{c|}{} & Average & Minimum & Maximum & Standard deviation \\
\hline Orbis & 98.93 & 10.26 & 183.76 & 36.73 \\
\hline Dębica & 119.65 & 84.06 & 176.99 & 19.85 \\
\hline PGF & 129.79 & 77.70 & 209.72 & 29.24 \\
\hline Kęty & 131.10 & 62.03 & 241.33 & 43.13 \\
\hline PKN Orlen & 151.95 & 112.80 & 211.78 & 22.46 \\
\hline Budimex & 157.01 & 89.99 & 222.73 & 29.53 \\
\hline Pekao & 159.28 & 101.93 & 212.35 & 23.55 \\
\hline BZ-WBK & 165.63 & 114.73 & 234.18 & 26.27 \\
\hline Amica & 169.16 & 99.80 & 312.45 & 46.61 \\
\hline BPHPBK & 171.23 & 121.15 & 235.71 & 23.98 \\
\hline Świecie & 173.64 & 75.90 & 590.97 & 89.55 \\
\hline Bre Bank & 180.15 & 119.52 & 297.32 & 33.61 \\
\hline Agora & 196.86 & 118.97 & 308.17 & 47.20 \\
\hline KGHM & 201.03 & 135.20 & 308.91 & 37.80 \\
\hline Computerland & 201.33 & 132.90 & 314.90 & 38.91 \\
\hline TP SA & 214.76 & 136.88 & 297.13 & 34.70 \\
\hline Comarch & 226.84 & 146.01 & 349.75 & 40.66 \\
\hline Prokom & 233.35 & 138.75 & 338.09 & 45.94 \\
\hline Bank Millennium & 237.30 & 116.03 & 424.97 & 78.78 \\
\hline Softbank & 294.29 & 183.73 & 569.40 & 70.67 \\
\hline Source: 0w & & & \\
\hline
\end{tabular}

Source: own research.

Those partnerships which have been regarded as the least risky in terms of average value of $R G$ show quite low values of standard deviation. The Dębica and Orbis partnerships are the leaders.

The third group is also specific. Some kind of regularity can be noticed namely the higher the $R G$ level, the higher the standard deviation, which, to some extent, is also a classic risk measure. The worst results are observed in Softbank and Bank Millennium. It is also significant that in the last group there are also partnerships form the data communication line of business, even Polish Telecommunication (Telekomunikacja Polska).

Figure 2, which is a graphic representation of the values from Table 2, confirms the above conclusions. The partnership Świecie should be taken into account as its range is very wide and what follows, the value of standard deviation is also meaningful. Therefore, it is important to qualify its securities as the most risky. 


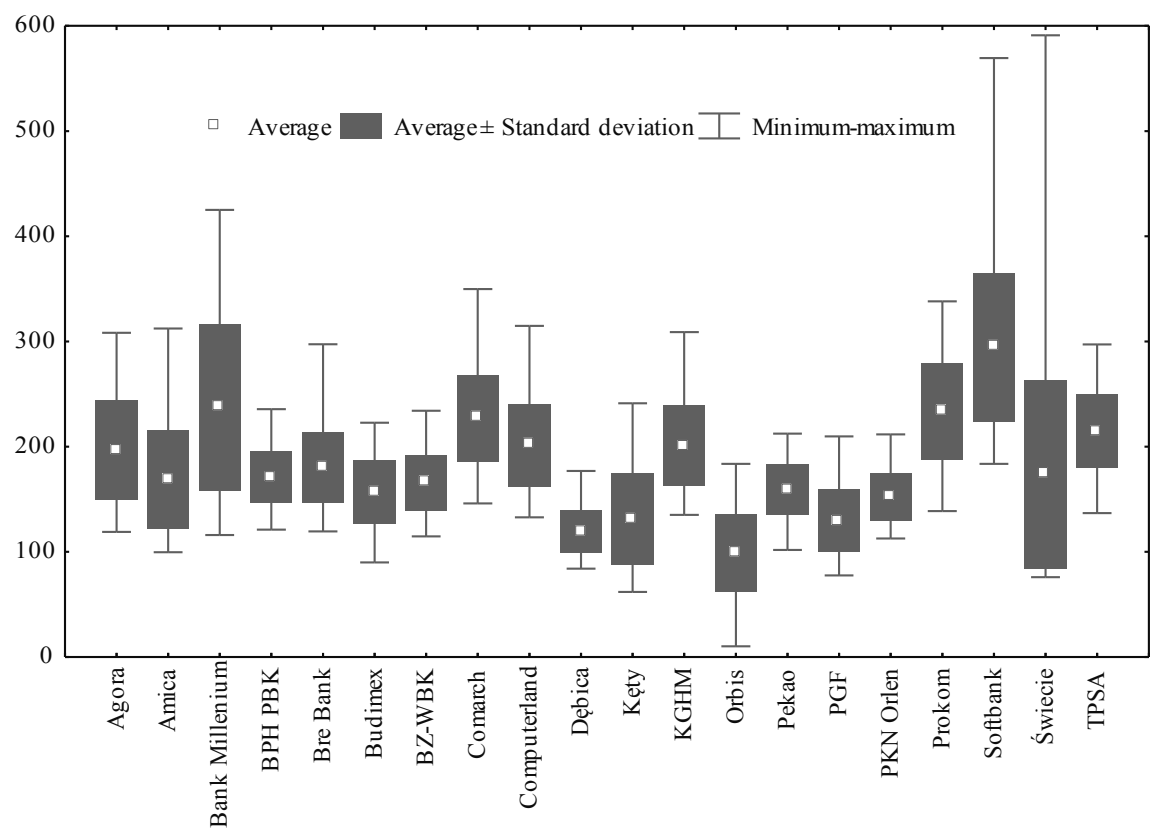

Fig. 2. Minimum, maximum and average RiskGrade for the partnerships of the WIG20 Source: own research.

\section{RiskGrade (RG) for investment portfolio}

RiskGrade can also be calculated for an investment portfolio. We need to use the following formula ${ }^{3}$

$$
R G_{t}^{(P)}=\frac{\sigma_{t, 252}^{(P)}}{0.2} \cdot 100=\frac{\sqrt{252} \cdot \sigma_{t, 1}^{(P)}}{0.2} \cdot 100
$$

where:

$\sigma_{t, 1}^{(P)}-$ standard deviation of daily logarithmic returns of the portfolio value:

$r_{t, 1}^{(P)}=\sum_{i=1}^{N} \omega_{i} \cdot r_{t, 1}^{(i)}, \omega_{i}-$ share of an $i$-th instrument in the portfolio value $\sum_{i=1}^{N} \omega_{i}$,

$r_{t, 1}^{(i)}$ - daily logarithmic returns of the portfolio components.

Estimations for $\sigma_{t, 1}^{(P)}$ are determined on the basis of historical records and with the application of the formula:

$$
\sigma_{t, 1}^{(P)}=\sqrt{\left(\omega_{1}, \ldots, \omega_{N}\right) \cdot V C V_{t, 1} \cdot\left(\omega_{1}, \ldots, \omega_{N}\right)^{T}}
$$


where: $V C V_{t, 1}$ - matrix of variance and covariance for daily logarithmic returns of the portfolio components.

Variances of daily returns of the portfolio components are estimated from the formula: $\sigma_{t, 1}^{(i)}=\sqrt{\frac{1-\lambda}{1-\lambda^{n}} \sum_{j=0}^{n} \lambda^{j} \cdot r_{t-j, 1}^{2}}$, and the covariances for the daily returns of the portfolio components from the formula: $\sigma_{t, 1}^{(i, j)}=\sqrt{\frac{1-\lambda}{1-\lambda^{n}} \sum_{k=0}^{n} \lambda^{k} \cdot r_{t-k, 1}^{(i)} \cdot r_{t-k, 1}^{(j)}}, \lambda=0,97, n=151$.

\section{The application of RiskGrade (RG) methodology while determining the optimum investment portfolio for a stock investor}

Suppose that an investor while considering the optimum composition of his investment portfolio took into account 20 biggest partnerships quoted in the Warsaw Stock Exchange. As the measure of investment risk the RiskGrade was applied. The investor, while establishing the composition of his optimum portfolio, could choose the weight for the particular components in such a way that the risk could be minimized (formulated by RG), with additional conditions put on big enough (expected) return of values of the investment portfolio ${ }^{4}$. First of all they should solve the following decisive task (7):

$$
\begin{gathered}
R G_{t}^{(P)}\left(\omega_{1}, \ldots, \omega_{N}\right) \rightarrow \min , \\
\left\{\begin{array}{l}
\bar{R}_{t, k}^{(P)}\left(\omega_{1}, \ldots, \omega_{N}\right) \geq R_{0}, \\
0 \leq \omega_{i} \leq \omega_{0}, i=1, \ldots, N, \\
\sum_{i=1}^{N} \omega_{i}=1 ; \quad R_{0}=\text { const }, \quad \omega_{0}=\text { const }
\end{array}\right.
\end{gathered}
$$

where:

$\bar{R}_{t, k}^{(P)}\left(\omega_{1}, \ldots, \omega_{N}\right)=\sum_{i=1}^{N} \omega_{i} \cdot \bar{R}_{t, k}^{(i)}$ - expected average return of portfolio value in a given time horizon of ,,$k$ days- (e.g. $k=252$ days-annual horizon).

$\bar{R}_{t, k}^{(i)}$ is estimated as a weighed average from the historical relative changes in an assumed time horizon of portfolio components.

Suppose that an investor who invests in shares in the Warsaw Stock Exchange has assumed that the expected annual return of the values of his investment portfolio should be at least $R=5 \%$ and they have decided that they won't invest in a single partnership more than 
$\omega_{0}=40 \%$ of the portfolio value. The results obtained to solve the decisive problem (7) which present the composition of the optimum investor's portfolio determined in various periods and on the basis of a bulk of historical data have been presented in Table 3. We can notice some partnerships which haven't been chosen for the optimum portfolio. These are: Agora, Comarch, Computerland, KGHM, Prokom, Softbank, TP SA, i.e. the partnerships of the higher risk.

Table 3. Composition of optimum investment portfolio in the analyzed time periods for $\omega_{0}=0,4 ; R_{0}=5 \%$

\begin{tabular}{|c|c|c|c|c|c|c|c|c|c|}
\hline & $\begin{array}{c}30 \\
\text { III } \\
2001 \\
\end{array}$ & $\begin{array}{c}04 \\
\text { VII } \\
2001 \\
\end{array}$ & $\begin{array}{c}02 \\
\text { IX } \\
2001 \\
\end{array}$ & $\begin{array}{c}04 \\
\text { I } \\
2002 \\
\end{array}$ & $\begin{array}{c}05 \\
\text { IV } \\
2002 \\
\end{array}$ & $\begin{array}{c}08 \\
\text { VII } \\
2002 \\
\end{array}$ & $\begin{array}{c}04 \\
\text { IX } \\
2002 \\
\end{array}$ & $\begin{array}{c}09 \\
\text { I } \\
2003 \\
\end{array}$ & $\begin{array}{c}10 \\
\text { IV } \\
2003 \\
\end{array}$ \\
\hline \multicolumn{10}{|l|}{ Agora } \\
\hline Amica & & & & & & 0.008 & 0.086 & 0.180 & \\
\hline Bank Millennium & & & & & & & 0.131 & & \\
\hline ВРНРВK & 0.235 & 0.244 & 0.264 & & 0.025 & 0.017 & 0.009 & 0.086 & \\
\hline Bre Bank & 0.118 & & & & & & & 0.095 & \\
\hline Budimex & & & & & 0.040 & 0.066 & 0.038 & 0.046 & 0.057 \\
\hline BZ-WBK & 0.138 & 0.057 & & & & & & & 0.037 \\
\hline \multicolumn{10}{|l|}{ Comarch } \\
\hline \multicolumn{10}{|l|}{ Computerland } \\
\hline Dębica & & & & & 0.061 & 0.259 & 0.246 & 0.264 & 0.110 \\
\hline Kęty & & & & 0.237 & 0.077 & 0.221 & & 0.206 & 0.046 \\
\hline \multicolumn{10}{|l|}{ KGHM } \\
\hline Orbis & & & & & & & & 0.015 & 0.241 \\
\hline Pekao & 0.350 & 0.352 & 0.400 & 0.331 & 0.147 & 0.042 & & 0.030 & 0.202 \\
\hline PGF & 0.103 & 0.261 & 0.030 & 0.100 & 0.397 & 0.040 & 0.090 & 0.075 & 0.263 \\
\hline PKN Orlen & & & & & & 0.059 & & & \\
\hline \multicolumn{10}{|l|}{ Prokom } \\
\hline \multicolumn{10}{|l|}{ Softbank } \\
\hline Świecie & 0.056 & 0.086 & 0.306 & 0.332 & 0.253 & 0.288 & 0.400 & 0.003 & 0.044 \\
\hline \multicolumn{10}{|l|}{ TP SA } \\
\hline RiskGrade optymalnego portfela & 98.8 & 86.5 & 96.5 & 77.9 & 71.6 & 48 & 50.4 & 62.9 & 65.3 \\
\hline
\end{tabular}

Source: own research.

To confirm such a behavior of the partnerships mentioned above we should look closer at the values of the expected annual returns of the analyzed partnerships (Figure 3 ), as for the discussed partnerships most of the values of average annual returns in the given time periods are below zero (making losses at the same time). 
There are also such partnerships which were taken into account in almost every period in the optimum portfolio. These are: PGF, Pekao, Świecie or BPHPBK - partnerships with low risk and expected positive or oscillating around zero annual returns.

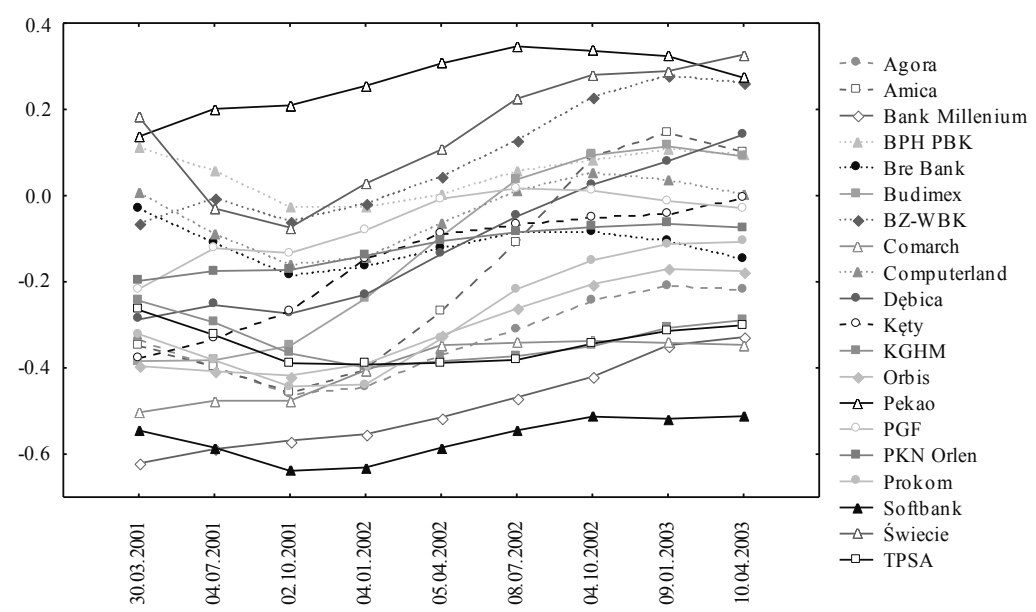

Fig. 3. Expected annual returns of potential portfolio components in given periods Source: own research.

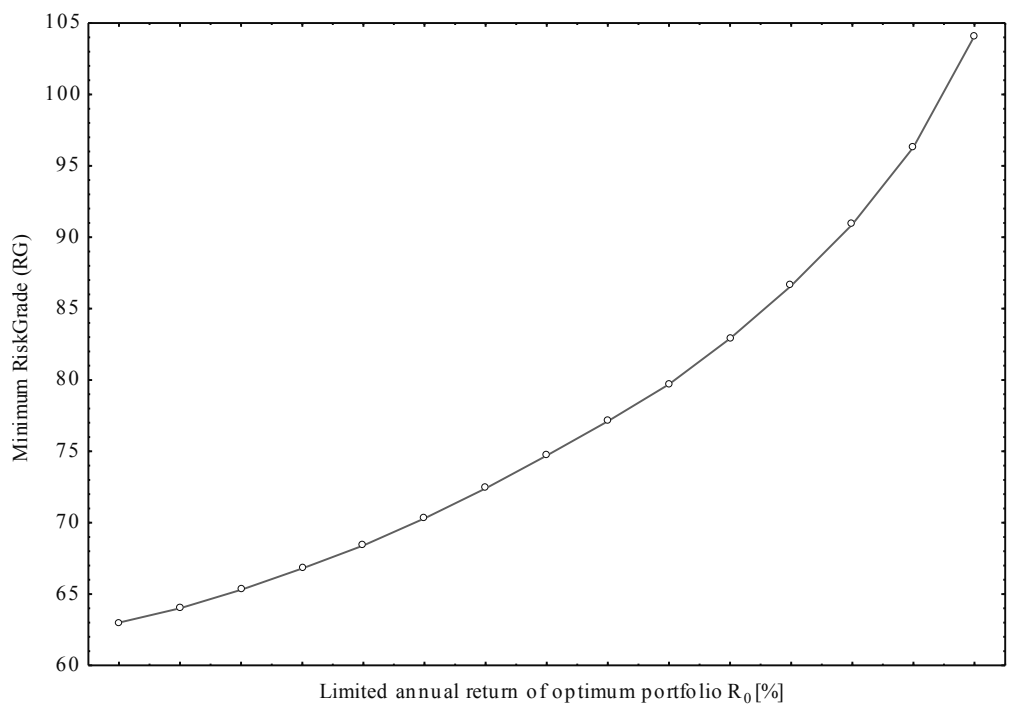

Fig. 4. Relation between minimum grade $(R G)$ and the assumed expected annual return of portfolio value for the optimum investment established on 10 April 2003 from optimum partnerships which form WIG20 index

Source: own research. 
Figure 4 shows how the risk of optimum investment portfolio will change when an investor expects much higher profit in values of his portfolio than assumed $5 \%$. Of course, higher profit in values of portfolio requires incurring a higher risk (higher $R G$ values).

\section{RiskImpact $(R I)$, that is an "impact" on the risk of the whole portfolio and some of its components}

If there is no correlation between components of the investment portfolio (correlation coefficient $=1)$ then there is the situation where $\sigma_{t, 1}^{(P)}<\sum_{i=1}^{N} \omega_{i} \cdot \sigma_{t, 1}^{(i)}$, and then: $R G_{t}^{(P)}<\sum_{i=1}^{N} \omega_{i} \cdot R G_{t}^{(i)}$ . The risk formulated by $R G$ of the portfolio due to its diversification on some of the components is lower than a weighted average risk calculated on the basis of $R G$ of its components. Such an effect is called RiskGrade Diversification Benefit and is demonstrated by the value of $R G$ index for the portfolio 5 .

$$
R G \operatorname{Div} B_{t}^{(P)}=\sum_{i=1}^{N} \omega_{i} \cdot R G_{t}^{(i)}-R G_{t}^{(P)} \geq 0
$$

The impact on the risk of the whole portfolio described by $R G$ of some of the portfolio component can be measured by the so-called RiskImpact (RI) index.

where:

$$
R I_{t}^{(P)}(i)=\frac{R G_{t}^{(P)}-R G_{t}^{(P)}(i)}{R G_{t}^{(P)}} \cdot 100[\%]
$$

$R G_{t}^{(P)}-$ RiskGrade for investment portfolio,

$R G_{t}^{(P)}(i)-$ RiskGrade for investment portfolio without a given instrument.

RiskImpact index describes how many percent the risk of the given investment portfolio (expressed by RG) can be reduced by, if the investor sells their shares invested in the ,i-th" component of the portfolio, and the profits will be kept in cash, for which, in case of the local stock exchange investor, the risk of loss does not exist $(R G=0)$. Table 4 shows the already calculated indices for the given optimum investment portfolio.

Figure 5 shows changes dynamics of $R G$ value for the components and the whole optimum investment portfolio in the given time period (from June 2000 to April 2003), as well as the values of the $R G D i v B$, which describes the rate of risk diversification for the portfolio. 
Table 4. Risk indices for the optimum investment portfolio established on 10 April 2003

\begin{tabular}{|c|c|c|}
\hline $\begin{array}{l}\text { Components of optimum portfolio } \\
\text { established on } 10.04 .03\end{array}$ & $\begin{array}{c}\text { Weights } \omega_{i} \\
\text { of optimum portfolio }\end{array}$ & $\begin{array}{c}\text { RiskImpact } R I_{t}^{(P)}(i) \\
\text { f (i) portfolio components }(\%)\end{array}$ \\
\hline Budimex & 0.057 & 5.1 \\
\hline BzWBK & 0.037 & 4.3 \\
\hline Dębica & 0.110 & 9.9 \\
\hline Kęty & 0.046 & 4.1 \\
\hline Orbis & 0.241 & 15.1 \\
\hline Pekao & 0.202 & 21.6 \\
\hline PGF & 0.263 & 18.9 \\
\hline Świecie & 0.044 & 5.2 \\
\hline $\begin{array}{c}\text { Portfolio RiskGrade }(\mathrm{RG}) \text { : } \\
\text { RGt }(\mathrm{P})=65,3 \\
\text { RiskGrade Div Benefit for portfolio: } \\
\text { RG DivB } \mathrm{t}(\mathrm{P})=42,1\end{array}$ & $\sum_{i} \omega_{i}=1$ & $\begin{array}{l}\sum_{i} R I_{t}^{(P)}(i)=84.2<100 \% \\
\text { (because } R G \operatorname{Div}_{t}^{(P)}>0\end{array}$ \\
\hline
\end{tabular}

Source: own research.

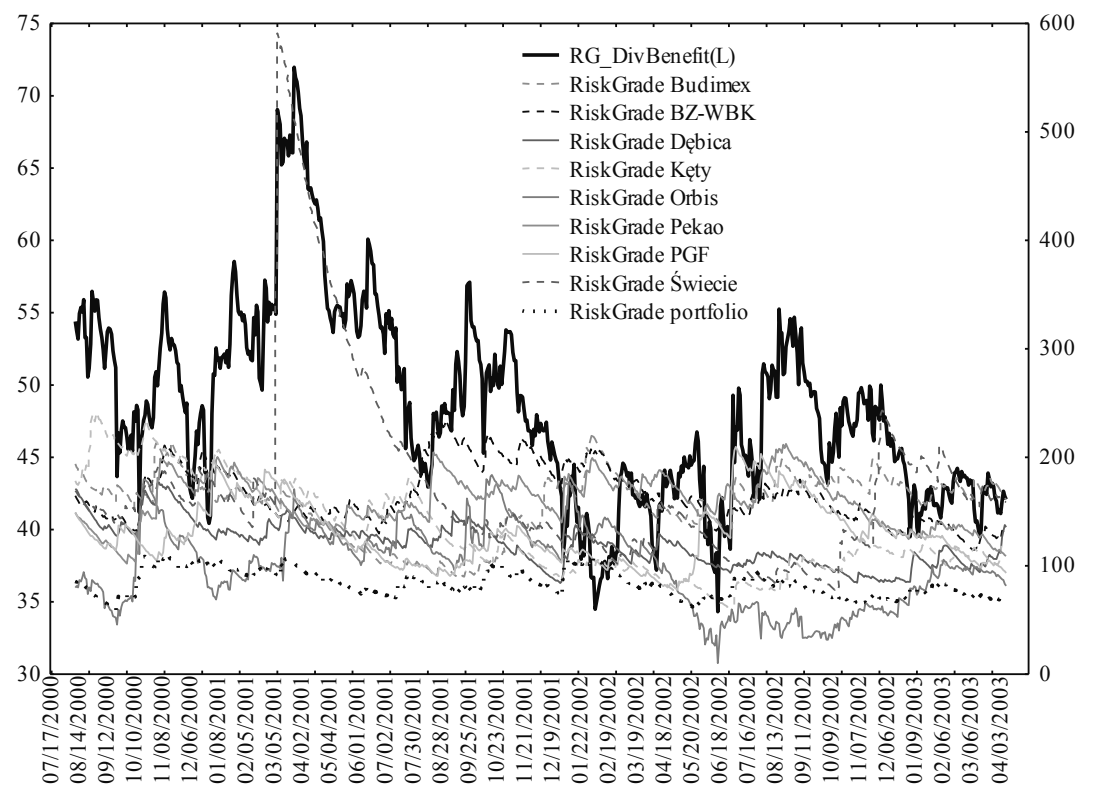

Fig. 5. Changes dynamics of RiskGrade for the optimum investment portfolio and its components established on 10.04 .03

Source: own research. 


\section{Chance of Losing Money - CLM}

It is a measure of the market risk for the portfolio of financial instruments in the long time horizon for the markets functioning in the standard conditions. It expresses the chance with which the value invested in the long time horizon (e.g. $k=21-$ monthly, $k=63$ - quarterly or $k=252$ - annually) can drop below the certain level (the level of losses). It can be determined according to the following formula

$$
\begin{gathered}
C L M^{(P)}=\operatorname{Pr}\left(Z S_{t, k}=P_{t+k}-P_{t}<z\right)=\int_{-\infty}^{z} f\left(x_{t, k}\right) d x= \\
=\operatorname{Pr}\left(r_{t, k}<r_{z}=\ln \left(1+\frac{z}{P_{t}}\right)\right)=\int_{-\infty}^{r_{z}} f\left(r_{t, k}\right) d r
\end{gathered}
$$

where:

$f\left(x_{t, k}\right), f\left(r_{t, k}\right)$ - functions of density of probability distribution,

$Z S_{t, k}$ - profits (losses) of portfolio and for the logarithmic portfolio returns in the time horizon of " $k$ " length.

This measure can be estimated (see Table 5) by applying:

- parametric methods - by using Random Walk process for modeling the changes in the logarithms of standard portfolio values. Then it is said that the logarithms ' $k$ ' - day returns of the portfolio values are modeled by the normal distribution: $r_{t, k}-N(k \cdot \mu, \sqrt{k} \cdot \sigma)$, where parameters $\mu, \sigma$ describe the behavior of daily $(\mathrm{k}=1)$ logarithmic returns of the portfolio values and they can be determined by means of the $M N W$ method on the basis of historical returns. Then CLM can be determined by means of the distribution function of the normal distribution;

- historical simulation method - by applying historical ( $k$-day) logarithmical returns of the portfolio values to estimate their empirical distribution of probability. On the basis of this distribution we can determine CLM.

\section{Xloss (eXpected Loss)}

It is another measure of market risk for the portfolio of financial instruments in a short (one-day) time horizon for the markets functioning in "abnormal" (non-standard) conditions. It expresses the average (anticipated) losses which can be borne in the value of the portfolio during the next day under the condition that at this day the losses will be higher than the 
Table 5. CLM measure for the optimum portfolio determined on 10 April 2003 by means of the parametric method and the method of historical simulation

CLM (historically) for the optimum portfolio of the value of 1000 PLN (\%)

\begin{tabular}{|l|c|c|c|c|}
\hline & \multicolumn{4}{|c|}{ Time horizon } \\
\hline $\begin{array}{l}\text { Losses value } \\
(\text { level } z \text { ) }\end{array}$ & $\begin{array}{c}k=1 \\
\text { (daily) }\end{array}$ & $\begin{array}{c}k=5 \\
\text { (weekly) }\end{array}$ & $\begin{array}{c}k=21 \\
\text { (monthly) }\end{array}$ & $\begin{array}{c}k=252 \\
\text { (annually) }\end{array}$ \\
\hline At least 10 PLN & 15.6 & 35.4 & 42.3 & 46.2 \\
\hline At least 20 PLN & 3.7 & 23.0 & 35.5 & 44.1 \\
\hline At least 50 PLN & 0.1 & 3.1 & 16.0 & 38.5 \\
\hline At least 100 PLN & 0.0 & 0.1 & 3.8 & 33.7 \\
\hline At least 150 PLN & & 0.0 & 0.1 & 0.1 \\
\hline At least 300 PLN & & & 0.0 & 0.0 \\
\hline At least 350 PLN & & & & 25.1 \\
\hline
\end{tabular}

$C L M$ (parametrically) for optimum portfolio of the value of 1000 PLN (\%)

\begin{tabular}{|l|c|c|c|c|}
\hline & \multicolumn{4}{|c|}{ Time horizon } \\
\hline $\begin{array}{l}\text { Losses value } \\
(\text { level } z \text { ) }\end{array}$ & $\begin{array}{c}k=1 \\
\text { (daily) }\end{array}$ & $\begin{array}{c}k=5 \\
\text { (weekly) }\end{array}$ & $\begin{array}{c}k=21 \\
\text { (monthly) }\end{array}$ & $\begin{array}{c}k=252 \\
\text { (annually) }\end{array}$ \\
\hline At least 10 PLN & 20.1 & 35.4 & 42.7 & 47.9 \\
\hline At least 20 PLN & 4.6 & 22.6 & 35.7 & 45.8 \\
\hline At least 50 PLN & 0.0 & 2.8 & 17.5 & 39.4 \\
\hline At least 100 PLN & & 0.0 & 0.2 & 29.0 \\
\hline At least 150 PLN & & & 0.0 & 19.7 \\
\hline At least 300 PLN & & & & 3.1 \\
\hline At least 350 PLN & & & & 0.0 \\
\hline At least 500 PLN & & & & \\
\hline
\end{tabular}

Source: own research.

estimated ones in the scenario and determined by the ' $z$ ' level. This scenario assumes that the negative return which causes losses on the ' $z$ ' level is an extreme situation and appears very rarely with the accepted probability (e.g. $\alpha=0.05$ - once every 20 days or once a month). $X L$ can be determined in the following way ${ }^{7}$ :

$$
\begin{gathered}
X L^{(P)}=E\left[Z S_{t, 1} \mid Z S_{t, 1}<z\right]=\frac{P_{t}}{\alpha} \int_{-\infty}^{r_{z}} r_{t, 1} \cdot f\left(r_{t, 1}\right) d r, \\
r_{z}: \int_{-\infty}^{r_{z}} f\left(r_{t, 1}\right) d r=\alpha
\end{gathered}
$$


where:

$P_{t} \quad$ - up-to-date (in the 'f' moment) portfolio value,

$Z S_{t, 1}$ - function of daily profits (losses) of investment portfolio values,

$r_{t, 1} \quad$ - daily logarithmic portfolio returns,

$f\left(r_{t, 1}\right)-$ density function for daily logarithmic portfolio returns.

In order to calculate Xloss $(X L)$ one can apply the parametric method or the historical simulation method.

\section{Marginal Xloss $-M X L$}

This risk measure describes how many percent an investor can lower the anticipated losses for his investment portfolio (described by means of $X L$ ), when an investor will close his positions in the engaged in " $i$ " portfolio element, and the received income will be kept in cash which if there is no risk of exchange change of currencies cannot suffer the losses. Marginal Xlosses can be determined from the following formula ${ }^{8}$ :

where:

$$
M X L^{(P)}(i)=\frac{X L^{(P)}-X L^{(P)}(i)}{X L^{(P)}} \cdot 100[\%],
$$

$X L^{(P)}(i)$ - expected losses for portfolio without the ' $\mathrm{i}$ ' instrument.

Table 6. Risk measures for the expected daily losses for the optimum investment portfolio created on 10 April 2003 determined by the parametric method and historical simulation method

\begin{tabular}{|c|c|c|}
\hline $\begin{array}{c}\text { Data: } \\
P_{t}=1000 \text { PLN, } \alpha=0,05 .\end{array}$ & Parametric method & Historical simulation \\
\hline $\begin{array}{c}\text { Expected losses for portfolio: } \\
X L^{(P)}\end{array}$ & -25.0 PLN & -26.8 PLN \\
\hline Marginal Xlosses for portfolio without the partnership: & {$[\%]$} & {$[\%]$} \\
\hline$M L^{(P)}$ & 4.5 & 5.7 \\
\hline Budimex & 3.4 & 3.1 \\
BzWBK & 7.5 & 8.6 \\
Dębica & 2.5 & 3.0 \\
Kęty & 25.7 & 23.2 \\
Orbis & 16.7 & 13.0 \\
Pekao & 19.6 & 24.0 \\
PGF & 2.9 & 3.1 \\
\hline Świecie & $\Sigma=82.8 \%<100 \%$. & $\Sigma=83.7 \%<100 \%$. \\
& (as there is XL DivB) & (as there is XL DivB) \\
\hline
\end{tabular}

Source: own research. 


\section{Remarks on RiskGrade determining for bonds and options}

\section{RiskGrade for bonds with fixed interest:}

1. Determine the market price of a bond in the ' $t$ ' moment on the basis of discounted values of its interest coupons and the nominal value:

$$
P_{t}=\sum_{j=1}^{n \cdot m} \frac{M \cdot i}{\left(1+y_{t} / m\right)^{j}}+\frac{M}{\left(1+y_{t} / m\right)^{n \cdot m}}
$$

where:

$n$ - number of years; $m$ - number of interest payments during a year,

$y_{t}$ - annual income rate from the bonds in the purchase period,

$i$ - fixed interest rate of a bond,

$M$ - nominal value of a bond.

2. Determine daily income of $r_{1, t}$ (logarithmic return) which results from the daily changes in the value of a bond and $r_{2, t}$ the daily interest rate of the income from a bond in the period for the purchase:

$$
r_{1, t}=\ln \left(P_{t}\right)-\ln \left(P_{t-1}\right), \quad r_{2, t}=\frac{y_{t}}{252}
$$

3. Sum up both ingredients and get daily return of $r_{t}$ for a bond:

$$
r_{t}=r_{1, t}+r_{2, t}
$$

4. Construct the simulation artificial time sequences for the bonds returns and determine $\mathrm{RG}-$ as it was discussed earlier for this action.

\section{RiskGrade for an option:}

1. Determine the market price of option in the ' $t$ ' moment on the basis of current values and factors which shape the price of the option.

The current option value is the function of: the price of the preliminary instrument $S_{t}$, price $X$, the length of the period from the moment of option expiry $-T$, the change of prices of a preliminary instrument $\sigma_{t}$, the rate free of risk $-i_{t}$ and the dividend $-D$ :

$$
C_{t}=F\left(S_{t}, X, T, \sigma_{t}, i_{t}, i_{t}, D\right)
$$


2. Determine the time sequence $C_{t-j}$ - of artificial (simulated) values of option price in the ' $t-j$ ' moment $(j=1,2, \ldots)$ on the basis of real historical changes in values: the price of preliminary instrument $-S_{t}$ and the rate free of risk $-i_{t}$ :

$$
C_{t-j}=F\left(S_{t}\left(1+r s_{t-j}\right), X, T, \sigma_{t}, i_{t}\left(1+r i_{t-j}\right), D\right)
$$

where:

$r s_{t-j}$ - return of prices of preliminary instrument in the ' $t-j$ ' moment;

$r i_{t-j}-$ return of rate free of risk in the ' $t-j$ '.

3. Determine the simulated historical logarithmic return for the option price of $r c_{t-j}$ from the formula:

$$
r c_{t-j}=\ln \left(C_{t-j}\right)-\ln \left(C_{t}\right)
$$

4. Construct the simulated artificial time sequences for the options returns and determine $\mathrm{RG}$ - as it was discussed earlier.

\section{Conclusions}

Introduced by RiskMetrics risk measure, which is RiskGrade, is a very good and universal risk measure that has many important features. It enables an investor to assess the risk of its investment portfolio and its components straight away. It also lets them calculate the risk for the derivatives. This measure applied as the criterion for the optimum choice of investment portfolio can be also verified and supported by the additional interesting risk measure.

On the basis of the RiskGrade methodology an investment portfolio was set up which consisted of the shares of some partnerships that constitute the WIG20 index. The characteristic features of the portfolio are the following:

- Quite low risk grade $(R G=65)$, assuming that the expected annual return from its value is $5 \%$,

- If such a bad scenario reappears, which happened once per month in the past, then the investor can lose daily (in the worst case) from 25 PLN to 27 PLN ( $X L$ measure informs about such cases),

- The strongest impact on daily losses in values of the investment portfolio has been observed in the following partnerships: Orbis (from 23-26\%), PGF (from 20-24\%) and Pekao (from 13-17\%). It results mainly from the biggest shares of these partnerships in the total portfolio value. 
The above analyses concerning the efficiency of the investment portfolio confirm vast application possibilities of RiskGrades methodology. These are very interesting tools and each potential stock investor who is looking for ways to support their decision should get familiar with them.

To sum up we can enumerate some significant features of the measure itself:

- RiskGrades is a scaled risk measure, based upon financial assets volatility (with the values $0-1000$, and even more), where $R G=100$ is equivalent of annual volatility equal $20 \%$ which is the weighted average annual volatility of the group of international indices,

- It is a measure whose values change dynamically in time, thanks to it investors can more efficiently control their investment portfolio,

- Compared to other classical measures of volatility it adjusts in a better way to the market conditions - due to the volatility estimation with the application of historical observations weighted by means of exponential weights,

- Compared to classic measures $R G$ is easier and more intuitive in its interpretation,

- It is a relative risk measure, thanks to which there is a possibility to compare investment risk within the group of assets, among various groups, and also for investors who come from different geographical regions,

- It takes into account all kinds of unrest which appear on financial markets (as in the past: Asian Crisis on 2 July 1997 or Russian Crisis on 21 August 1999).

\section{Notes}

1 See Kim, Mina (2001).

2 Ibidem.

3 Ibidem.

4 See Jajuga K., Jajuga T. (2000), Kim, Mina (2001).

5 See Kim, Mina (2001).

6 Ibidem.

7 See Jajuga K., Jajuga T. (2000).

8 Kim, Mina (2001). 


\section{References}

Jajuga, K. (1993). Zarządzanie kapitałem, Wrocław: Wydawnictwo AE we Wrocławiu.

Jajuga, K., Jajuga, T. (1993). Jak inwestować w papiery wartościowe, Warszawa: PWN.

Jajuga, K., Jajuga, T. (2000). Inwestycje. Instrumenty finansowe. Ryzyko finansowe. Inżynieria finansowa, Warszawa: PWN.

Kim J., Mina, J. (2001). RiskGrades Technical Document, RiskMetrics (www.riskmetrics. com).

Tarczyński, W. (1997). Rynki kapitałowe, Warszawa: Agencja Wydawnicza Placet.

Tarczyński, W., Zwolankowski, M. (1999). Inżynieria finansowa. Instrumentarium. Strategie. Zarządanie ryzykiem, Warszawa: Agencja Wydawnicza Placet.

Weron, A., Weron, R. (1999). Inżynieria finansowa, Warszawa: WNT. 